Position Paper

\title{
Hemostatic balance in patients with liver cirrhosis: Report of a consensus conference
}

\author{
Under the auspices of the Italian Association for the Study of Liver Diseases \\ (AISF) and the Italian Society of Internal Medicine (SIMI)
}

\section{A R T I C L E I N F O}

\section{Article history:}

Received 27 January 2016

Accepted 18 February 2016

Available online 27 February 2016

\section{Keywords:}

Bleeding

Cirrhosis

Hemostasis

Thrombosis

\begin{abstract}
A B S T R A C T
Patients with cirrhosis present with hemostatic alterations secondary to reduced availability of procoagulant and anti-coagulant factors. The net effect of these changes is a rebalanced hemostatic system. The Italian Association of the Study of the Liver (AISF) and the Italian Society of Internal Medicine (SIMI) promoted a consensus conference on the hemostatic balance in patients with cirrhosis. The consensus process started with the review of the literature by a scientific board of experts and ended with a formal consensus meeting in Rome in December 2014. The statements were graded according to quality of evidence and strength of recommendations, and approved by an independent jury. The statements presented here highlight strengths and weaknesses of current laboratory tests to assess bleeding and thrombotic risk in cirrhotic patients, the pathophysiology of hemostatic perturbations in this condition, and outline the optimal management of bleeding and thrombosis in patients with liver cirrhosis.
\end{abstract}

(C) 2016 Published by Elsevier Ltd on behalf of Editrice Gastroenterologica Italiana S.r.l.

\section{Introduction}

Hemostatic alterations are common in patients with cirrhosis. For a long time it was believed that a defective synthesis of pro-coagulant factors together with thrombocytopenia increased the risk of bleeding but protected against thrombosis in these patients. Accordingly diagnostic and therapeutic invasive procedures in patients with cirrhosis were considered risk factors for bleeding. However, this belief has been challenged by evidence of a concomitant decrease of anti-coagulant factors. The net effect of these changes is a rebalanced hemostasis. However, this hemostatic profile is unstable, and patients can be tipped toward both bleeding and thrombosis under certain conditions [1-5]. Thus,

Angelo Andriulli ${ }^{\mathrm{a}, *}$, Armando Tripodi ${ }^{\mathrm{b}, \mathrm{c}}$, Paolo Angeli ${ }^{\mathrm{d}}$, Marco Senzolo ${ }^{\mathrm{e}}$, Massimo Primignani ${ }^{\mathrm{f}}$, Edoardo G. Giannini ${ }^{\mathrm{g}}$, Oliviero Riggio ${ }^{\mathrm{h}}$, Agostino Colli $^{\mathrm{i}}$, Daniele Prati $^{\mathrm{j}}$, David Sacerdoti ${ }^{\mathrm{d}}$, Carlo Merkel $^{\mathrm{d}}$, Stefania Basili ${ }^{\mathrm{k}}$, Domenico Ferro ${ }^{\mathrm{k}}$, Erica Villa ${ }^{1}$, Giovanni Di Minno ${ }^{\mathrm{m}}$, Paolo Caraceni ${ }^{\mathrm{n}}$, Marco Marzioni ${ }^{\circ}$,

Pier Mannuccio Mannucci ${ }^{\mathrm{f}}$, Francesco Violi ${ }^{\mathrm{k}}$,

a Division of Gastroenteroloy, Casa Sollievo Sofferenza Hospital, IRCCS, San Giovanni Rotondo, Italy

b-o See Appendix A.

* Corresponding author. Tel.: +39 0882 410263; fax: +39 0882835411. there is growing evidence that proper understanding of the hemostatic pathways in liver disease requires a global perspective which account for the complexity of hemostasis, with dynamic interactions between pro-coagulant and anti-coagulant factors.

\section{Methods}

A consensus meeting promoted by the Italian Association for the Study of the Liver and the Italian Society of Internal Medicine was held to discuss limitations of current laboratory tests for the assessment of bleeding and thrombotic risk, and to review the management of bleeding and thrombosis in patients with cirrhosis. A scientific board of experts was initially appointed to identify relevant topics relating to alterations of coagulation in cirrhotics. Subsequently, relevant literature data pertaining to each of the 5 identified major topics was conducted by several ad hoc subcommittees of experts with the aim to highlight areas with high-quality and/or uncertainty; the sub-committee work ended with the formulation of several statements. The process ended with a formal consensus meeting held in Rome in December 5 and 6, 2004, when the statements were finalized, graded according to quality of evidence and strength of recommendations, and finally approved by an independent jury. The quality of evidences and strength of 
recommendations were graded according to the GRADE system (Table S1).

\section{Laboratory tests to assess bleeding}

\subsection{Bleeding time}

In patients with cirrhosis, bleeding time is prolonged [6], but the clinical meaning of this laboratory alteration is uncertain as values were not predictive of bleeding secondary to liver biopsy [7] or esophageal variceal rupture [8]. Even in settings other than cirrhosis, the test had no predictive value for bleeding [9]. Furthermore, a randomized clinical trial on patients with variceal bleeding aimed at testing the efficacy of desmopressin (a drug known to shorten the bleeding time) combined with terlipressin, was interrupted prematurely because of excess hemorrhagic events in the desmopressin arm [10].

Statement. Bleeding time should not be used in patients with cirrhosis as a screening test to predict the risk of esophageal varices bleeding or bleeding following invasive procedures (A2).

\subsection{Platelet count}

Patients with cirrhosis present with variable degrees of thrombocytopenia [11] and increased levels of the adhesive protein von Willebrand factor (VWF) which facilitates in vitro platelets to adhere and aggregate normally [2]. When the platelet count was adjusted to a standard value of $100 \times 10^{9} / \mathrm{L}$, platelet-rich plasma from patients with cirrhosis generated in vitro as much thrombin as that of healthy subjects [12]. Although the benefit of platelet infusion to avoid bleeding in cirrhotics has never been assessed in clinical trials, counts of $60 \times 10^{9} / \mathrm{L}$ are considered sufficient to secure in vitro thrombin generation at the lower reference limit [12]. In hepatitis C-related cirrhosis, platelet numbers of $\leq 60 \times 10^{9} / \mathrm{L}$ were associated with an increased risk of procedurerelated bleeding [13]. The practice of transfusing one single adult platelet dose only to patients with cirrhosis and counts $<50 \times 10^{9} / \mathrm{L}$ undergoing variceal banding elevates circulating platelet counts only marginally, with no or little effect on thrombin generation and thromboelastometry [14].

Statement. Platelet counts $\geq 50 \times 109 / L$ are considered to ensure normal primary hemostasis $(B)$.

\subsection{Prothrombin time}

The prothrombin time (PT), with results expressed as international normalized ratio (INR), is the standard test to monitor therapy with vitamin $\mathrm{K}$ antagonists (VKA). In cirrhosis, PT prolongation parallels impairment of the synthetic capacity of the liver has been used to assess bleeding risk. However, increasing evidence suggests that PT (and other congener tests) poorly reflects the hemostatic balance in cirrhosis. In these patients, reduced levels of pro-coagulants are counteracted by a parallel reduction of their anti-coagulant counterparts [4]. The paradoxical prolongation of the PT, in spite of normal thrombin generation, stands to the fact that the PT is more sensitive to the reduction of procoagulants than to the reduction of anti-coagulants, especially of protein C. Protein C, which is reduced in cirrhosis, must be activated to express its full anti-coagulant activity. In addition, its main physiological activator, thrombomodulin, is located in endothelial cells but not in plasma nor in reagents used to estimate the PT. Previous observations are in line with the long lasting evidence that the PT is a poor predictor of peri- or post-operative bleeding in cirrhosis [15-22]. Furthermore, a powerful pro-hemostatic agent, such as recombinant activated factor VII (rFVIIa), although capable of considerably shortening the PT [23], proved to be ineffective to stop esophageal bleeding $[23,24]$, or to reduce bleeding at surgery $[25,26]$.

Statement. Current evidence does not support the use of PT values as predictors of bleeding or to monitor the effectiveness of hemostasis-modifying therapy in patients with cirrhosis (A2).

\subsection{Thromboelastometry/thromboelastography}

Whole blood viscoelastic tests evaluate the kinetics of coagulation, from initial clot formation to final clot strength. The viscoelastic properties of blood components are assessed in vitro by the thromboelastometry/thromboelastography (ROTEM/TEG) techniques. Due to the reagents used for testing (i.e. citrated whole blood, which includes plasma, erythrocytes, leukocytes and platelets), these tests should, at least in principle, reflect the global coagulation occurring in vivo better than other conventional plasma-based tests. Although data from clinical trials are lacking, these tests are widely used in the setting of liver transplantation to manage major hemorrhage or to trigger blood transfusion. Even in this setting, the threshold values of ROTEM/TEG parameters for triggering transfusion of hemostatic agents (such as fresh frozen plasma), remains to be determined [27], even though in a randomized study significantly fewer units of fresh frozen plasma (FFP) or blood were needed at the time of liver transplantation in patients monitored by TEG [28]. These promising results warrant larger confirmatory studies.

Statement. The use of algorithms based on thromboelastometry/thromboelastography (ROTEM/TEG) may facilitate targeted transfusions with hemostatic agents, such as fresh frozen plasma, in patients undergoing liver transplantation or in those with severe bleeding (C2). However, the threshold values of these tests to target transfusion requirement need to be established in appropriate clinical trials.

\subsection{Thrombin generation assays}

Thrombin generation assays (TGA) assess the time course of thrombin generation and its decay when plasma is triggered by small amounts of tissue factor and phospholipids. Because of their design, TGA approximate the in vivo coagulation balance better than conventional coagulation tests (PT/activated partial thromboplastin time [APTT]). When evaluated by TGA, patients with cirrhosis have the potential to generate as much thrombin as healthy subjects after thrombomodulin addition [1,4]. Patients with cirrhosis and relatively high levels of thrombin generation present with a hypercoagulable state in vitro [29] and may be at risk of thrombotic events. By the same token, patients with relatively low levels may be at increased hemorrhagic risk. However, clinical trials are warranted to test this hypothesis.

Statement. Thrombin generation assays are promising laboratory tools which may help stratify patients with cirrhosis at risk for hemorrhage or thrombosis (C2). Before their implementation in clinical practice is recommended effectiveness should be tested in clinical trials.

\subsection{Fibrinolysis}

Under physiological conditions, plasminogen-to-plasmin conversion is regulated by profibrinolytic drivers [i.e., tissue plasminogen activator [t-PA], urokinase plasminogen activator and activated factor XII]. These effects are opposed by antifibrinolytic drivers (i.e., t-PA inhibitors (PAI-1), plasmin inhibitor (PI) and thrombinactivable fibrinolysis inhibitor (TAFI)]. Perturbations of this balance 
may result in hyperfibrinolysis or hypofibrinolysis. Plasma hyperfibrinolysis has been reported in patients with cirrhosis [30], but its mechanism in bleeding is still debated [31] due to lack of adequate laboratory tests for its evaluation. Available observations are based on the evaluation of individual components of fibrinolysis, but not on the overall action of both pro- and anti-fibrinolytic drivers, as it occurs in vivo. Cirrhosis has been associated with laboratory changes suggesting hyperfibrinolysis (i.e., increased t-PA and reduced PI or TAFI), but also with changes suggesting hypofibrinolysis (i.e., reduced plasminogen and increased PAI). Despite conflicting data, the balance of fibrinolysis is likely restored by concomitant changes in the pro- and anti-fibrinolytic drivers [3,32,33].

Statement. Although hyperfibrinolysis may favor bleeding in patients with cirrhosis, the steps in fibrinolytic process cannot be assessed by currently available laboratory tests (C).

\section{Laboratory tests to assess a hypercoagulable state}

\subsection{Testing for thrombophilia}

In the population without cirrhosis, congenital deficiencies of anti-coagulants or acquired increased levels of pro-coagulants, or both are risk factors for thrombosis. In patients with cirrhosis, thrombophilic parameters, such as anti-thrombin, protein C, protein $\mathrm{S}$, the Leiden gain-of-function polymorphisms of factor $\mathrm{V}$, or the prothrombin gene gain-of-function mutation have been investigated in order to assess their usefulness in stratifying patients at risk for portal vein thrombosis (PVT). A recent meta-analysis questioned the utility of anti-thrombin, protein $\mathrm{C}$, and protein $\mathrm{S}$ levels to predict PVT [34], while measurement of congenital deficiencies of anticoagulants may be informative in patients with cirrhosis and a personal or familial history of thrombosis. Carriers of polymorphisms of factor $\mathrm{V}$ or prothrombin gene were at increased risk of PVT [35], as were those with increased levels of factor VIII [36]. Anti-phospholipid syndrome also carries a risk for thrombosis in the population without cirrhosis; however, the laboratory diagnosis of this syndrome which is based on phospholipid-dependent coagulation tests, is unreliable in patients with cirrhosis, who have abnormal coagulation tests at baseline. Anticardiolipin (aCL) and anti-Beta2-glycoprotein I (a-Beta2-GPI) might better serve to detect this condition.

Statement. Due to impairment of the liver synthetic function, anti-thrombin, protein $C$ and protein $S$ are abnormally low in patients with cirrhosis. Their levels (measured with standalone assays) should not be used to evaluate the risk of thrombosis (A1). In patients with cirrhosis and personal or familial history of thrombosis, evaluation of factor $V$ Leiden, prothrombin gene polymorphisms, and factor VIII plasma levels may be useful in stratifying the risk of portal vein thrombosis (B2). The diagnosis of anti-phospholipid syndrome is currently hampered by the intrinsic limitations of coagulation tests in patients with cirrhosis (A). Searching for anti-cardiolipin and anti-beta2-glycoprotein seems promising for this purpose $(C)$, but further investigation is required.

\subsection{Thrombin generation assays}

The ratio of endogenous thrombin potential with or without thrombomodulin parallels the severity of cirrhosis, and correlates with increased levels of factor VIII, reduced levels of protein C, and their ratios [29]. These results were confirmed when, instead of thrombomodulin, Protac (a non-physiologic protein $C$ activator) was used for testing [37]. Resistance to anti-coagulant action of thrombomodulin or Protac is recognized as a risk factor for venous thromboembolism in patients without cirrhosis. Whether or not this in vitro resistance might be associated with the risk of peripheral vein thrombosis or PVT in patients with cirrhosis is still unknown.

Statement. Thrombin generation assay with/without thrombomodulin or Protac might be useful to assess the risk for venous thromboembolism in patients with cirrhosis (C). Nevertheless, further investigations are needed before their use is recommended in clinical practice.

\section{Coagulation tests as prognostic markers}

As most coagulation factors are synthesized by the liver, global and specific coagulation assays reliably indicate the severity of cirrhosis and patient prognosis. Both the Child-Turcotte-Pugh score (CTP) and the model for end stage liver disease (MELD), which incorporate the PT value in the models, proved to be effective in assessing survival. The assumption that in liver cirrhosis the INR yields the same numerical results when measured in different laboratories using different thromboplastins is still accepted [38]. However, depending on the thromboplastin used in the assay, the INR measured for an individual patient may vary across laboratories [39], thus introducing a bias into the CTP and MELD scores which may affect the priority for liver transplantation $[40,41]$. There have been attempts to solve this issue by two groups who proposed new systems for INR standardization: the INR-liver (valid for patients with cirrhosis) and the INR-VKA (valid for patient on VKA) [40,41]. These methods have not yet been endorsed by scientific societies or regulatory authorities.

Statement. The PT/INR test contributes to the Child-TurcottePugh and model for end-stage liver disease (MELD) scores, and is considered a reliable index for grading the severity of liver impairment (A1). However, there is some concern about the reporting of this parameter using the common INR scale. Implementation of the INR-liver or any other effective system of standardization is warranted.

\section{Monitoring anti-thrombotic therapy}

In patients with cirrhosis VTE may occur either in portal or peripheral veins $[42,43]$. When VTE occurs, the use of anti-coagulants (heparins and VKA) becomes an option. Anticoagulation with s.c. LMWH or fondaparinux, or with intravenous unfractionated heparin (UFH) was initially recommended for acute VTE in non-liver disease patients. In patients with cirrhosis, a major concern regarding the use of heparins is the reduction of anti-thrombin, as parentally administered drugs need to bind antithrombin to exert their action. On the other hand, it has not yet been established whether in patients with cirrhosis the INR interval used in the general population for monitoring anti-coagulation, may be applied. Accordingly, laboratory monitoring and management of patients with cirrhosis while on anti-coagulants requires special expertise.

\subsection{Unfractionated heparin}

UHF is administered as intravenous injection and requires laboratory monitoring using the APTT assay, with a therapeutic interval set at 1.5-2.5 times prolongation over baseline. This interval depends heavily on the reagent/instrument used for testing. The 1.5-2.5 APTT value corresponds approximately to $0.3-0.7 \mathrm{U} / \mathrm{mL}$ of anti-Xa. However, as for the APTT, standardization of anti-Xa assays and their therapeutic intervals have not yet been established. Due to these as well as other limitations (e.g., heparin induced thrombocytopenia, osteoporosis, etc.), UFH use has been gradually replaced by LMWH. 
Statement. When monitoring unfractionated heparin (UFH) therapy, the APTT test may vary between centers depending on the reagent locally used $(C)$. Furthermore, APTT is often prolonged in cirrhosis, so UFH will probably be under-dosed when the criterion of 1.5-2.5 APTT prolongation over baseline is applied (C). Consequently, intravenous UFH is not recommended in cirrhosis (A1).

\subsection{Low molecular weight heparin (LMWH)}

In patients without cirrhosis, LMWH is administered subcutaneously once daily or twice daily in a fixed dose for thromboprophylaxis, and a weight-adjusted dose for therapeutic purposes. Laboratory monitoring is not mandatory but is required in special circumstances, such as obesity, renal insufficiency or pregnancy. Fondaparinux is administered subcutaneously once daily in a fixed dose, and no laboratory monitoring is required. Thus, the main question is whether or not fixed- or weightadjusted LMWH doses, which are effective and safe in non-liver disease patients, are equally so in patients with cirrhosis. In nonrandomized studies $[44,45]$, LMWH administration at a fixed dose was effective and safe in patients with established PVT. In vitro the anti-Xa assay proved suboptimal for monitoring LMWH use $[46,47]$, while TGA was more appropriate [47]. An in vitro study also suggested that, despite of a lower anti-thrombin level, plasma from patients with cirrhosis was more responsive to LMWH than that from healthy subjects [47]. The only available randomized trial showed that LMWH at a fixed dose and without laboratory monitoring was effective and safe in preventing PVT in patients with cirrhosis [48].

Statement. For prophylaxis or treatment of portal vein thrombosis, low molecular weight heparin (LMWH) at fixed or weight-adjusted doses does not require laboratory monitoring (C2). In patients with cirrhosis, it is not known whether or not LMWH requires laboratory monitoring, while the anti-FXA assay does not reflect the achieved anti-coagulation with a given dosage of LMWH (C2).

\subsection{Vitamin K antagonists (VKA)}

For dose-adjustment of VKA administration in non cirrhotic patients, the test to be used is the PT, with results expressed as INR (here called INR-VKA, see above for more details) and set at a therapeutic interval of 2.0-3.0 (target 2.5). Whether these same intervals apply to patients with cirrhosis has not yet been established. Regarding the APPT, the baseline PT is often prolonged in patients with cirrhosis. Thus, lower VKA doses would probably be required to achieve the optimal therapeutic interval; however, this issue has not yet been addressed. As previously mentioned, VKA are used in patients with cirrhosis; a further concern is using the INR to report the PT results. The common INR (INR-VKA) is a reliable index of the anti-coagulation level in non-liver disease patients, but may be suboptimal in patients with cirrhosis $[40,41]$.

Statement. Vitamin $K$ antagonist (VKA) should be administered to attain an INR value of 2.0-3.0 (C). However, due to the limitation of this scale in cirrhosis, the INR value might not be representative of the real anti-coagulation achieved (C2), and results may vary between centers $(A)$. Randomized trials to assess and monitor the efficacy and safety of VKA in cirrhosis are needed.

\section{Factors tipping the hemostatic balance in cirrhosis}

Factors that may impair the hemostatic balance in patients with cirrhosis are of intrinsic (i.e., liver-related) or extrinsic origin (i.e., superimposed on the liver disease).
Concerning the intrinsic factors, a pro-hemorrhagic tendency may be secondary to thrombocytopenia [49,50]. Alcohol might affect hemostasis by inducing dietary deficiencies which impair megakaryocyte maturation, inhibit platelet aggregation, and reduce global fibrinolytic capacity [51-55]. Definite evidence for impaired fibrinolysis in alcohol misusers is still needed, as previous studies assessed single components of the fibrinolytic system. In patients with primary biliary cirrhosis or sclerosing cholangitis, a hypercoagulable state has been related to hypofibrinolysis, high levels of coagulation factors and hyper homocysteinemia [56-58]. In non-alcoholic steatohepatitis, a tendency to a pro-coagulant state, characterized by increased factor VIII and reduced protein C, is common [59]. Portal hypertension, which causes thrombocytopenia, may entail a hemorrhagic diathesis. In addition, porto-systemic shunting and gut barrier disruption facilitate endotoxaemia and contribute to the hemorragic diathesis [60].

The endothelium helps to hemostasis, as VWF, t-PA and PAI1 are derived predominantly from endothelial cells. In cirrhosis, endothelial dysfunction has been surmised by the observation of changes in levels of nitric oxide-derived by-products [61,62], flow mediated vasodilatory response of the brachial artery [63] and VWF levels [64-68]. Currently, there is no single marker that can detect endothelial dysfunction in patients with cirrhosis.

Among extrinsic factors, bacterial infections are frequent in hospitalized patients with cirrhosis, and often responsible for acute on chronic liver failure $[69,70]$. The condition may favor a hemorrhagic diathesis through a direct effect of bacterial products or the hyper-production of proinflammatory cytokines, causing defects in platelet aggregation [71], coagulation activation and hyperfibrinolysis [72-74], and release of endogenous heparinoids [75-77]. Deficiency in protein $C$ activity, reported in patients with cirrhosis and severe sepsis, may precipitate disseminated intravascular coagulation [78]. Moreover, an imbalance of VWF and its cleaving protease ADAMTS13 induced by systemic inflammation was reported in cirrhosis [79]. Bacterial translocation may act either as a pro-hemostatic or an anti-hemostatic factor. Chronic endotoxinrelated inflammation may raise the risk of PVT in cirrhosis [72,80]. Endotoxins favor a pro-thrombotic diathesis by increasing portal hypertension and slowing portal flow through endothelin-induced contraction of hepatic stellate cells [80], and/or by increasing the production of endothelium-associated factors [68]. In addition, endotoxemia may trigger coagulation activation [68] in patients treated with non-absorbable antibiotics, a treatment that induces a concomitant reduction in endotoxemia and thrombin generation $[81,82]$.

Finally, patients with cirrhosis are at risk of developing both acute and chronic kidney disease [83-87]. In the general population, chronic renal disease is associated with a high thrombotic risk, while in acute renal failure the bleeding risk prevails over that of thrombosis. The hemostatic balance in patients with concomitant liver cirrhosis and acute or chronic renal disease has not been specifically investigated.

Statement. The etiology and severity of liver disease may alter the hemostatic balance in both directions. Endothelial dysfunction and bacterial translocation may induce a pro-thrombotic effect, while bacterial infection or sepsis may provoke a prohemorrhagic effect. Studies assessing the hemostatic balance in patients with cirrhosis and acute or chronic kidney disease are lacking (B).

\section{Risk of bleeding following invasive procedures or surgery}

The majority of studies that assessed the risk of bleeding in relation to platelet count and/or results of coagulation tests in patients 
Table 1

Post-procedural bleeding in cirrhotic patients, in relation to platelet counts and INR values.

\begin{tabular}{|c|c|c|c|c|}
\hline Procedures & Study references & Bleeding following the procedure & Low platelet count $\left(\leq 50-60 \times 10^{9}\right)^{\mathrm{a}}$ & INR $>1.5$ no \\
\hline Paracentesis & {$[19,88-91]$} & $0.3-3 \%$ & No & No \\
\hline Thoracentesis & {$[92,93]$} & $2 \%$ & Unknown & Unknown \\
\hline Percutaneous liver biopsy & {$[13,94-97]$} & $0.5 \%$ & Yes & Likely \\
\hline Transjugular liver biopsy & {$[98-100]$} & $<1 \%$ & Unknown & Unknown \\
\hline Dentistry & {$[101,102]$} & $2.9 \%$ & No & No \\
\hline Endoscopic variceal ligation & {$[103,104]$} & $3-7.3 \%$ & No & No \\
\hline Endoscopic polypectomy & {$[105,106]$} & $3-12.4 \%$ & No & No \\
\hline Percutaneous ablation HCC & {$[107,110]$} & $1 \%$ & Unknown & Unknown \\
\hline OLT & {$[28,111-114]$} & & No & No \\
\hline Liver surgery & [115] & $3.9-6.6 \%$ & No & No \\
\hline Cholecystectomy & {$[116,117]$} & $3.9-6.6 \%$ & No & No \\
\hline Hernioplasty & {$[118,119]$} & $2.3-10.8 \%$ & Unknown & Unknown \\
\hline
\end{tabular}

a Definition of the low threshold value varied among studies but is usually taken as $\leq 50 \times 10^{9}$.

with cirrhosis undergoing invasive procedures or surgery were retrospective, and adopted a priori cut-offs for laboratory values (Table 1) $[13,19,28,88-118]$. In one study with a stringent inclusion criterion for platelet counts of $>50 \times 10^{9} / \mathrm{L}$, a platelet count of $\leq 60 \times 10^{9} / \mathrm{L}$ was identified as a risk factor for bleeding after percutaneous liver biopsy [13]. Moreover, in several studies, the enrolled population consisted of patients with and without cirrhosis, and some underwent prophylactic platelets or plasma transfusions, possibly jeopardizing the interpretation of results. Lastly, for some procedures, there is no comparison with risk in patients without cirrhosis. Despite these non-negligible limitations, it appears that the bleeding rate after paracentesis, thoracentesis, and percutaneous or transjugular liver biopsy is low $(<3 \%)$, and moderate $(<10 \%)$ following endoscopic variceal ligation, endoscopic polypectomy, and minor abdominal surgery such as cholecystectomy or hernioplasty. In general, abnormal coagulation parameters did not predict procedure-related bleeding, while various degrees of thrombocytopenia were associated with post-procedural bleeding.

Statement. In patients with cirrhosis, procedure-related bleeding is uncommon (B), and standard coagulation tests are not good predictors of post-procedure bleeding. Although formal trials are lacking, thrombocytopenia (i.e., platelet count $<50-60 \times 10^{9} / \mathrm{L}$ ) may be predictive of bleeding.

\section{Pharmacologic interventions to control or prevent bleeding}

\subsection{Recombinant activated factor VII}

rFVIIa promotes hemostasis by binding to the surface of platelets activated at sites of vascular injury, and by directly activating factor $\mathrm{X}[24,119,120]$. In patients with and without liver diseases, administration of rFVIIa shortened the abnormal PT value [119-124]. However, in randomized clinical trials rFVIIa administration to patients with cirrhosis proved ineffective in controlling bleeding from varices or bleeding during surgery [24,120,125-127].

Statements. rFVIIa administration shortens the prothrombin time in patients with cirrhosis. However, this laboratory effect did not translate into clinical benefits (A1).

\subsection{Platelet transfusion}

In patients with cirrhosis an adequate amount of thrombin is generated in vitro when platelet counts approximate $50-60 \times 10^{9} / \mathrm{L}$, optimal levels being seen with counts $>100 \times 10^{9} / \mathrm{L}$ [12]. However, the clinical value of these thresholds remains obscure, as at lower counts interaction of platelets with coagulation pathways is still seen in vivo. Platelet transfusion is still employed to reach such thresholds [128,129], but this practice lacks evidence-based support. Rheological studies indicated that normal platelet flow was adversely affected whenever hematocrit levels dropped to $<25 \%$, supporting the claim that this level should be maintained in patients with cirrhosis who bleed [130]. One unit of platelet concentrate $\left(300 \pm 30 \times 10^{9} / \mathrm{L}\right)$ for every $10 \mathrm{~kg}$ of body weight is usually administered, and platelet count needs to be checked after $1 \mathrm{~h}$ [130]. However, a correlation between improved platelet counts and enhanced hemostasis has never been shown [13]. After transfusion of one platelet unit, thrombin generation remained unaffected and ROTEM parameters did not return to normal [14].

Statement. Current guidelines recommend platelet transfusion when counts are $<50 \times 10^{9} / \mathrm{L}$; however, this recommendation is supported only by biological plausibility (C2).

\subsection{Eltrombopag}

Eltrombopag is an agonist of the thrombopoietin receptor, and its administration results in enhanced platelet production [131-135]. In HCV infected patients with thrombocytopenia, platelet numbers increased up to $100 \times 10^{9} / \mathrm{L}$ or more in a dosedependent manner in $75 \%, 79 \%$ and $95 \%$ of patients after the use of 30,50 and $75 \mathrm{mg}$ of eltrombopag, respectively [136]. In patients with thrombocytopenia undergoing invasive procedures, eltrombopag at a dose of $75 \mathrm{mg}$ daily for 14 days allowed platelet transfusion to be avoided in $72 \%$ of cases; however, six patients treated with the active drug and two with placebo experienced a thrombotic event. A post hoc analysis showed that platelet counts $\geq 200 \times 10^{9} / \mathrm{L}$ were associated with thrombosis [136]. Further exploration of eltrombopag therapy is warranted, including better identification of risk factors for thrombosis, dose optimization, and patient selection.

Statement. Eltrombopag is not indicated for reducing the units of platelet concentrates to be infused at the time of invasive procedures, as post-procedural bleeding did not differ between treated and untreated patients (A1).

\subsection{Vitamin $K$}

Vitamin $\mathrm{K}$ is necessary for the carboxylation of coagulation factors II, VII, IX, and X. Intravenous injection of $10 \mathrm{mg}$ daily of vitamin $\mathrm{K}$ for 24-48 h may restore vitamin deficiency secondary to cholestasis or malabsorption [137]. However, in patients with impaired synthetic liver function, administration of vitamin $\mathrm{K}$ is ineffective in normalizing PT/INR values [137-139].

Statement. Routine administration of vitamin $K$ is not recommended to increase the plasma levels of coagulation factors in patients with cirrhosis, (B1). 


\subsection{Fresh frozen plasma}

FFP shortens an abnormal PT in various clinical conditions, including cirrhosis. However, PT (or APTT) shortening does not necessarily translate into improved bleeding control. Furthermore, the dilution of coagulation factors contained in the FFP and their relatively short half-life of $8-48 \mathrm{~h}$ demands large volumes to be infused [141]. Indeed, to increase the activity of coagulation factors by $1-2 \%$, FFP needs to be infused at a dosage of $1 \mathrm{~mL} / \mathrm{kg}$ body weight [142], with repeated infusions every $6-12 \mathrm{~h}$ [142]. These therapeutic end-points are hardly attainable in patients with cirrhosis, as large volumes of FFP may result in excessive plasma expansion and increased intracerebral pressure [143].

FFP infusion is commonly used before surgical/invasive procedures in patients with an INR $\geq 2$ or PT prolongation $>4$ s [140]. Nevertheless, this practice is not evidence-based. The threshold for administering FFP was arbitrarily set at the $50 \%$ value of normal PT (i.e., INR of 2). For intracranial pressure monitoring, the threshold was raised to $80 \%$ of normal PT (i.e., an INR of approximately 1.2-1.3) [140]. During massive blood transfusion, FFP administration was advised at a ratio of $1: 2$ with red cells infusion, to avoid dilution of coagulation factors [144]. In patients with INR $>1.5$, FFP was administered at a dosage of $12-15 \mathrm{~mL} / \mathrm{kg}$ before liver biopsy, but evidence was not provided on whether or not this practice improved clinical outcomes [146]. In two studies this regimen allowed correction of PT in only $20 \%$ of patients receiving $900 \mathrm{~mL}$ of FFP $[145,146]$. The infusion of $<500 \mathrm{~mL}$ of FFP seldom corrects the PT by more than $2-3$ s $[142,147]$. In vitro, the addition of FFP to plasma of patients with cirrhosis proved ineffective in increasing thrombin generation [148,149]. It is important to realize that cut-off values for PT employed to trigger infusion are arbitrarily set and not based on clinical trial data. The myth of infusing FFP to treat the coagulopathy of patients with cirrhosis still dominates clinical practice, but evidence based on clinical trials is lacking.

Statement: Infusion of fresh frozen plasma may improve or even normalize some coagulation parameters in patients with cirrhosis, but the need to infuse high volumes makes this practice potentially unsafe (A1). The clinical benefit of infusing fresh frozen plasma in patients with cirrhosis undergoing invasive procedures lacks experimental evidence, and this practice is not routinely recommended $(B 2)$.

\subsection{Prothrombin complex concentrates}

Prothrombin complex concentrates are a mixture of vitamin $\mathrm{K}$ dependent coagulation factors, which are present at 20 -fold higher concentration than in a unit of FFP [150]. Administration of prothrombin complex concentrates improves PT in about $50 \%$ of patients with cirrhosis $[145,149]$. This improvement was attained at a mean dosage of $1500 \mathrm{~mL}$, and associated with an increase in thrombin-antithrombin complexes, that are markers of excessive in vivo thrombin generation [149]. Thrombotic events did not occur during infusion, but other complications, including heparininduced thrombocytopenia, were observed $[151,152]$. Thrombosis may be of more concern when a concomitant reduction in anticoagulant factors is common. In a single study on patients with cirrhosis, the infusion of a four factors complex concentrate allowed safe execution of interventional procedures with no complications [152]. However, the sample size of this uncontrolled study was small.

Statement: In patients with cirrhosis, the infusion of prothrombin complex concentrates improves PT/INR values. Further studies are needed before their use in clinical practice is recommended (C2).

\subsection{Desmopressin}

Desmopressin, an analog of the antidiuretic hormone, increases plasma levels of factor VIII and VWF, probably by increasing their secretion from endothelial storage sites [153]. In patients with liver failure, its administration at a dose of $0.3 \mathrm{mg} / \mathrm{kg}$ shortened the bleeding time [154]. However, the clinical benefit of this effect remains to be verified. In a randomized trial, terlipressin was administered as monotherapy or in association with desmopressin to control variceal bleeding: no clinical benefit emerged [10]. Desmopressin failed to decrease blood transfusion requirement during hepatic resection [155]; in managing bleeding following dental extraction, the drug was not more effective than blood transfusion [156].

Statement. Desmopressin use is not recommended in patients with cirrhosis undergoing elective surgery or at the time of variceal bleeding (B2). Desmopressin administration in patients with cirrhosis undergoing dental extraction may be considered (B2).

\subsection{Antifibrinolytics}

The use of aprotinin, a serine inhibitor which antagonizes various proteases [157], has been extensively studied in liver transplantation [158], but only one randomized trial evaluated its efficacy in 97 patients with cirrhosis: intra-operative blood loss and blood transfusion were significantly lower in the treatment group compared to placebo [159]. The efficacy of another serine protease inhibitor, nafamostat mesilate, was evaluated in 22 patients who underwent hepatic resection for hepatocellular carcinoma: despite laboratory evidence of control of hyperfibrinolysis, blood loss was not different in the treated and control groups [160]. Epsilon aminocaproic acid interferes with plasminogen binding to fibrin, thus inhibiting the conversion of plasminogen to plasmin [161]. Similarly, tranexamic acid inhibits fibrinolysis by competitively inhibiting plasminogen at 6-10-fold higher potency than epsilon aminocaproic acid [162]. In the frame of a randomized trial on 214 patients undergoing surgery, tranexamic acid administered before surgery allowed a blood transfusion-free hepatectomy [163]. In a meta-analysis of 23 studies including a total of 1407 patients with cirrhosis undergoing liver transplantation, both aprotinin and tranexamic acid reduced transfusion requirements compared to controls. No hepatic artery or venous thromboembolic events were documented following the administration of either drugs [164]. Before dental extractions, four $\times 100 \mathrm{mg}$ mouthwashes of tranexamic acid for a week can be used to reduce bleeding [102]. Tranexamic acid has also been useful in reducing blood transfusion requirements in patients with cirrhosis and gastric antral vascular ectasia who did not respond to endoscopic treatment [165].

Statement. Tranexamic acid and aprotinin reduce blood loss after hepatic resection and, together with Epsilon aminocaproic acid, reduce blood loss in liver transplantation and should be recommended in hepatic surgery (A1). In patients with cirrhosis, mouth washes with tranexamic acid after dental extraction could be considered (C2), but no evidence for the efficacy of the drug in other cirrhosis conditions is available (C2).

\section{Portal and peripheral vein thrombosis}

\subsection{Venous thromboembolism in liver cirrhosis}

Since thrombin generation in patients with cirrhosis is normal, owing to the preserved balance between pro- and anti-coagulants, the risk for VTE is not reduced as previously believed, but rather 
Table 2

Incidence of VTE in patients with chronic liver disease or cirrhosis.

\begin{tabular}{|c|c|c|c|c|c|}
\hline & Type of study & Patients, $n$ & Controls, $n$ & VTE cases & VTE incidence (follow up) \\
\hline Garcia-Fuster, 2008 [166] & Retrospective cohort & 2074 CC & - & 17 & $0.8 \%$ ( 16 years) \\
\hline Dabbagh, 2010 [167] & Retrospective cohort & $190 \mathrm{CLD}$ & - & 12 & $6.3 \%(7$ years $)$ \\
\hline Northup, 2006 [42] & Retrospective case-control & 21,000 hospitalized CC & 113 hospitalized CC without VTE & 113 & $0.5 \%$ ( 8 years $)$ \\
\hline Huerta, 2007 [168] & Retrospective case-control & $6550 \mathrm{VTE}$ & 10,000 no-VTE & - & $\begin{array}{l}74.5 \text { per } 100,000 \\
\text { person-years }\end{array}$ \\
\hline Gulley, 2008 [169] & Retrospective case-control & $963 \mathrm{CC}$ & 12,405 non-CC & $\begin{array}{l}18 \mathrm{CC} \\
121 \text { non-CC }\end{array}$ & $1.87 \%$ (10 years) \\
\hline Lizarraga, 2010 [170] & Retrospective case-control & 108 CLD with VTE & $\begin{array}{l}\text { Population: } 14,790 \text { CLD; } \\
\text { Control: } 108 \text { CLD no VTE }\end{array}$ & 108 & $0.73 \%$ ( 4 years) \\
\hline
\end{tabular}

CC: patients with cirrhosis; CLD: chronic liver disease; VTE: venous thromboembolism.

Table 3

Prevalence of VTE in patients with chronic liver disease or cirrhosis.

\begin{tabular}{|c|c|c|c|c|c|}
\hline & Type of study & Patients, $n$ & Controls & VTE cases & VTE prevalence \\
\hline Aldawood, 2011 [171] & Retrospective cohort & 226 CC & - & 6 & $2.7 \%$ \\
\hline Lesmana, 2010 [172] & Retrospective case-control & 12 CC with VTE & 244 CC without VTE & 12 & $4.7 \%$ \\
\hline Walsh, 2013 [173] & Retrospective case-control & 27 CLD with VTE & 81 CLD without VTE & 17 & $0.65 \%$ \\
\hline $\mathrm{Wu}, 2011[174]$ & $\begin{array}{l}\text { Population based } \\
\text { retrospective case-control }\end{array}$ & $\begin{array}{l}408,253 \mathrm{C}-\mathrm{CC} \\
241,626 \mathrm{D}-\mathrm{CC}\end{array}$ & 575,057 hospitalized non CC & $3307 ; 1981 ; 4370$ & $\begin{array}{l}0.81 \% \text { C-CC; } \\
0.82 \% \text { D-CC; } \\
0.76 \% \text { controls }\end{array}$ \\
\hline Saleh, 2011 [175] & $\begin{array}{l}\text { Population based } \\
\text { retrospective cohort }\end{array}$ & $\begin{array}{l}\text { 4,927,000 AlcCLD } \\
4,565,000 \text { nAlcCLD }\end{array}$ & - & $\begin{array}{l}\text { Alc CLD 30,000; } \\
\text { nAlcCLD 42,000 }\end{array}$ & $\begin{array}{l}0.6 \% \text { AlcCLD } \\
0.9 \% \text { nAlcCLD }\end{array}$ \\
\hline Ali, 2011 [176] & $\begin{array}{l}\text { Population based } \\
\text { retrospective cohort }\end{array}$ & 449,798 CC & - & 8321 & $1.8 \%$ \\
\hline
\end{tabular}

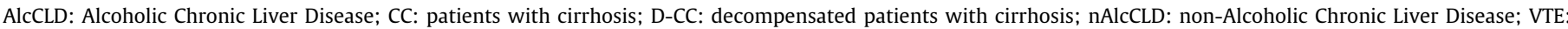
venous thromboembolism.

increased due to immobilization, surgery, concomitant diseases such as cancer and endothelial dysfunction. Estimates of VTE in patients with cirrhosis are discordant [42,43,166-176], due to retrospective collection of data, high heterogeneity of patients' characteristics, and study design. Reported rates range from $0.5 \%$ to $6.7 \%$ for incidence (Table 2), and from $0.6 \%$ to $4.7 \%$ for prevalence (Table 3), with higher values in patients with more severe liver disease [173] and in those with hepatocellular carcinoma [176]. Prophylaxis for VTE with anti-coagulants in patients with cirrhosis was shown to be safe and effective $[177,178]$.

Statement. Patients with cirrhosis are not protected against VTE and should not be precluded from receiving antithrombotic prophylaxis in conditions with increased risk for VTE (C2).

\subsection{Portal vein thrombosis in cirrhosis}

PVT is frequent in cirrhosis [35,48,179-190], with a 1-year incidence of 4.6-16.7\% (Table 4), and prevalence of 1.4-26.1\% (Table 5). Prevalence increases with the severity of cirrhosis [186,190], with rates of up to $44.4 \%$ in patients with hepatocellular carcinoma.

Slow portal blood flow, vessel wall damage and hypercoagulability are risk factors for PVT in patients with cirrhosis [191-193]. Other risk factors include male sex, previous abdominal surgery, encephalopathy, ascites, a low platelet count and a history of bleeding varices [35,184,194-198]. The role of inherited or acquired thrombophilia, as well as of previous sclerotherapy for variceal bleeding, is uncertain [35,184,194-198].
Doppler ultrasound is accurate for diagnosing thrombosis of the main portal vein and its intrahepatic branches, but false negative results may occur in cases with limited occlusion [199-201]. Multiphasic helical CT or MRI are recommended to confirm the finding and evaluate patency of the superior mesenteric vein (SMV), splenic veins, or the occurrence of portosystemic shunts. Classification of PVT is important for medical treatment and surgery and the Yerdel's classification which grades the length of portal vein involvement and its extension seems adequate [202]. PVT is classified as grade 1 when $<50 \%$ of the lumen is occluded with no or minimal extension to SMV; grade 2 when $>50 \%$ of the portal vein is occluded; grade 3 , when the portal veins and proximal SMV are occluded; grade 4 when the portal vein and SMV thromboses extend to their distal portions.

Statement. In patients with cirrhosis a Doppler ultrasound at 6month intervals should be implemented as a screening procedure for the detection of portal vein thrombosis (C1). Whenever thrombosis is encountered, CT scan/MRI are recommended to evaluate its extension, adopting the Yerdel's classification (B1).

\subsection{Impact of portal vein thrombosis on the natural history of} cirrhosis

The influence of PVT on the natural history of cirrhosis is debated. Partial PVT may progress to complete occlusion and/or extend to other splanchnic vessels in $40-70 \%$ of cases; conversely, spontaneous recanalization of occluded veins may occur $[203,204]$.

Table 4

Incidence of portal vein thrombosis (PVT) in cirrhosis of different etiology without hepatocellular carcinoma.

\begin{tabular}{|c|c|c|c|c|c|}
\hline & \multirow[t]{2}{*}{ Type of study } & \multirow[t]{2}{*}{ Study period } & \multirow[t]{2}{*}{ Number of patients } & \multicolumn{2}{|c|}{ Incidence of PVT } \\
\hline & & & & $n$ & $\%$ \\
\hline Zocco, 2009 [179] & Prospective cohort & Not specified & 73 & 12 & 16.4 \\
\hline Villa, $2012[48]$ & Prospective case-control & $2008-2010$ & 36 & 6 & 16.7 \\
\hline Maruyama, 2013 [180] & Retrospective case-control & 1998-2009 & 148 & 19 & 12.8 \\
\hline John, 2013 [181] & Prospective cohort & 2004-2009 & 243 & - & 8.4 \\
\hline Nery, 2015 [182] & Prospective case-control & 2000-2009 & 1243 & - & 4.6 \\
\hline
\end{tabular}


Table 5

Prevalence of portal vein thrombosis in cirrhosis of different etiology without hepatocellular carcinoma.

\begin{tabular}{|c|c|c|c|c|c|}
\hline \multirow[t]{2}{*}{ First author, year, reference } & \multirow[t]{2}{*}{ Type of study } & \multirow[t]{2}{*}{ Study period } & \multirow[t]{2}{*}{ Number of patients } & \multicolumn{2}{|c|}{ Prevalence of PVT } \\
\hline & & & & $n$ & $\%$ \\
\hline Violi, $1994[6]$ & Prospective case-control & 1990-1991 & 73 & 9 & 12.3 \\
\hline Amitrano, 2000 [35] & Prospective case-control & 1998-1999 & 328 & 26 & 7.9 \\
\hline Amitrano, 2004 [184] & Prospective case-control & 1998-2002 & 701 & 79 & 11.3 \\
\hline Robles, 2004 [185] & Prospective cohort & $1988-2001$ & 455 & 32 & 7.0 \\
\hline Fimognari, 2005 [186] & Prospective case-control & Not specified & 136 & 33 & 24.1 \\
\hline Lendoire, 2007 [187] & Retrospective case-control & 2005-2006 & 299 & 26 & 8.7 \\
\hline Weber, 2009 [188] & Retrospective case-control & 1998-2006 & 88 & 23 & 26.1 \\
\hline John, 2013 [181] & Prospective cohort & 2004-2009 & 290 & 70 & 24.1 \\
\hline Girleanu, 2014 [189] & Prospective cohort & 2011 & 1580 & 22 & 1.4 \\
\hline Berry, 2014 [190] & Retrospective cohort & $2002-2013$ & 66,506 & 2207 & 3.3 \\
\hline Nery, 2015 [182] & Prospective case-control & $2000-2006$ & 1278 & 35 & 2.7 \\
\hline
\end{tabular}

The impact of PVT on patients' outcome was prospectively evaluated in two studies [180,182]. In the Maruyama et al. study, occurrence of PVT, partial in most cases, affected neither the incidence of variceal bleeding nor patient' survival. In the Nery et al. study, PVT correlated with the severity of portal hypertension, but was not responsible for further liver impairment. In these patients, the rate of spontaneous recanalization of portal veins was exceptionally high (70\%), compared with only $1 / 41$ in the prospective study by Luca et al. [202]. Retrospective studies [43,181,203,205] yielded discordant data but overall indicated poorer survival in patients with stable or progressive PVT, if left untreated $[2,4,5]$. In addition, PVT in liver transplant candidates correlated with increased mortality after liver transplantation [206].

Statement. Complete or partial portal vein thrombosis (PVT) with extension to the superior mesenteric vein increases mortality in liver transplant candidates and in patients with variceal bleeding (B2). Monitoring of patients with isolated PVT by Doppler ultrasound is recommended, as the occlusion may extend in some patients and regress in others (B2).

\subsection{Anti-coagulation for the prevention/treatment of portal} vein thrombosis

The value of preventing PVT by the administration of anticoagulants in patients with cirrhosis has been established: in a controlled trial a 12-month course of enoxaparin was safe; in addition, no bleeding occurred in treated or untreated patients [48]. Although encouraging, these preliminary results need confirmation in further studies. The safety of longer regimens and in patients with more advanced cirrhosis, excluded from the cited trial, warrants further investigation.

Regarding the efficacy and safety of anti-coagulant therapy in patients with cirrhosis and established PVT, available data consist of 5 case series with a total of 163 subjects [204,207-210]: at month 6 of therapy, complete or partial recanalization occurred in 33-45\% of patients, while extension of the thrombus was observed in $<10 \%$. Factors predicting recanalization were recent onset ( $<6$ months) of the thrombus and partial PVT [211-213]. Treatment prolongation resulted in higher rates of recanalization and a lower likelihood of extension. Although the majority of treated patients recalled a past variceal bleeding or high-risk varices, a bleeding event was recorded in only $5 \%$. After anti-coagulation is stopped, the benefit wanes rapidly, as PVT recurred in $40 \%$ of patients.

There is no agreement on which anti-coagulant should be administered, as LMWH or VKAs have their own advantages and disadvantages. LMWH is as safe and effective as VKAs, but less practical because of the need for subcutaneous injections. LMWH does not interfere with the MELD score and may be used until transplantation. A platelet count $<50 \times 10^{9} / \mathrm{L}$ and the use of VKA were the only factors more frequently observed in patients with bleeding related to anti-coagulation therapy [207]. Direct oral anticoagulants (e.g., dabigatran, rivaroxaban, apixaban and edoxaban) are now available as substitutes for VKA in non-liver disease patients, but their effectiveness/safety in patients with chronic liver disease remains to be assessed.

Statement. Before starting anti-coagulation it is advisable to check for the presence of varices, initiate beta blockers treatment, or perform rubber band ligation in patients with large varices or in those with previous variceal bleeding (C2). Thrombosis prophylaxis should not be withheld from patients with cirrhosis (B2). In patients with cirrhosis and portal vein thrombosis, anticoagulation is safe and effective (B1). Prophylactic or elective treatment should be attempted by low molecular weight heparin (LMWH) or vitamin K antagonist (VKAs). In patients with platelet counts $<50 \times 10^{9} / \mathrm{L}, \mathrm{LMWH}$ could be the best choice (C2). In candidates for liver transplantation, anti-coagulation should be maintained until transplantation (2B). Whether or not long-term anti-coagulation should be maintained in patients with cirrhosis ineligible to transplantation remains to be established.

Conflict of interest

None declared.

\section{Appendix A. Co-author affiliations}

b Department of Clinical Sciences and Community Health, University of Milan, Milan, Italy

c IRCCS Cà Granda, Policlinico Hospital Foundation, Milan, Italy

d Department of Medicine, University of Padua, Italy

e Multivisceral Transplant Unit, Gastroenterology, Department of Surgery, Oncology and Gastroenterology, University Hospital, Padua, Italy

f Hemophilia and Thrombosis Center, IRCCS Fondazione Cà Granda, Policlinico Maggiore Hospital Foundation and University of Milan, Italy

g Gastroenterology Unit, Department of Internal Medicine, University of Genoa, Italy

$\mathrm{h}$ Gastroenterology, Department of Clinical Medicine, La Sapienza University, Rome, Italy

i Department of Internal Medicine, A Manzoni Hospital, Lecco, Italy

${ }^{\mathrm{j}}$ Department of Transfusion Medicine and Hematology, A Manzoni Hospital, Lecco, Italy

k Department of Internal Medicine, La Sapienza University, Rome, Italy

${ }^{1}$ Department of Gastroenterology, University of Modena and Reggio Emilia, Modena, Italy 
m Department of Clinical Medicine and Surgery, Federico II University, Naples, Italy

${ }^{\mathrm{n}}$ Department of Medical and Surgical Sciences, Alma Mater Studiorum University, Bologna, Italy

${ }^{\circ}$ Department of Gastroenterology, Università Politecnica delle Marche, Ancona, Italy

\section{Appendix B. Participants involved in the review}

Participants involved in the review of published evidence, and formulation of the proposed consensus statements, all of whom should be considered as co-authors of the present report.

Fabio Piscaglia, Bologna, Italy

Vincenza Calvaruso, Palermo, Italy

Lesley De Pietri, Milan, Italy

Marco Falcone, Rome, Italy

Paolo Feltracco, Padua, Italy

Elvira Grandone, San Giovanni Rotondo, Italy

Vincenzo La Mura, Milan, Italy

Anna Licata, Palermo, Italy

Cristina Lucidi, Rome, Italy

Sergio Maimone, Messina, Italy

Marco Marietta, Modena, Italy

Filomena Morisco, Naples, Italy

Laura Napoleone, Rome, Italy

Salvatore Piano, Padua, Italy

Valeria Raparelli, Rome, Italy

Paolo Rebulla, Milan, Italy

Dario Ribero, Milan, Italy

Maria Teresa Sartori, Milan, Italy

Antonella Scalera, Naples, Italy

Filippo Schepis, Modena, Italy

Massimo Sicilianom Rome, Italy

Gianluca Svegliati Baroni, Ancona, Italy

Antonella Tufano, Naples, Italy

Alessandro Vitale, Padua, Italy

Massimo Zuin, Milan, Italy

\section{Appendix C. Voting jury}

Chairmen: Roberto de Franchis (Milan, Italy), Pier Mannuccio Mannucci (Milan, Italy).

Members: Calogero Cammà (Palermo, Italy), Umberto Cillo (Padua, Italy), Alfredo Di Leo (Bari, Italy), Stefano Fagiuoli (Bergamo, Italy), Ivan Gardini (Vimercate, Italy), Angelo Gatta (Padua, Italy), Giacomo Laffi (Florence, Italy), Tecla Mastronuzzi (Bari, Italy), Renzo Pegoraro (Padua, Italy), Domenico Prisco (Florence, Italy), Francesco Salerno (Milan, Italy), Paolo Simioni (Padua, Italy).

\section{Appendix D. Supplementary data}

Supplementary material related to this article can be found, in the online version, at http://dx.doi.org/10.1016/j.dld.2016.02.008.

\section{References}

[1] Tripodi A, Salerno F, Chantarangkul V, et al. Evidence of normal thrombin generation in cirrhosis despite abnormal conventional coagulation tests. Hepatology 2005;41:553-8.

[2] Lisman T, Bongers TN, Adelmeijer J, et al. Elevated levels of von Willebrand Factor in cirrhosis support platelet adhesion despite reduced functional capacity. Hepatology 2006;44:53-61.

[3] Lisman T, Leebeek FW, Mosnier LO, et al. Thrombin-activatable fibrinolysis inhibitor deficiency in cirrhosis is not associated with increased plasma fibrinolysis. Gastroenterology 2001;121:131-9.

[4] Tripodi A, Mannucci PM. Mechanisms of disease. The coagulopathy of chronic liver disease. New England Journal of Medicine 2011;365:147-56.
[5] Violi F, Basili S, Raparelli V, et al. Patients with liver cirrhosis suffer from primary haemostatic defects? Fact or fiction. Journal of Hepatology 2011;55:1415-27.

[6] Violi F, Leo R, Vezza E, et al. Bleeding time in patients with cirrhosis: relation with degree of liver failure and clotting abnormalities. Coagulation Abnormalities in Cirrhosis Study Group. Journal of Hepatology 1994;20:531-6.

[7] Boberg KM, Brosstad F, Egeland T, et al. Is a prolonged bleeding time associated with an increased risk of hemorrhage after liver biopsy? Thrombosis and Haemostasis 1999;81:378-81.

[8] Basili S, Ferro D, Leo R, et al. Bleeding time does not predict gastrointestinal bleeding in patients with cirrhosis. Coagulation Abnormalities in Liver Cirrhosis. Journal of Hepatology 1996;24:574-80.

[9] Cosmi B, Alatri A, Cattaneo M, et al. Assessment of the risk of bleeding in patients undergoing surgery or invasive procedures. Thrombosis Research 2009;124:e6-12.

[10] De Franchis R, Arcidiacono PG, Carpinelli L, et al. Randomized controlled trial of desmopressin plus terlipressin vs. terlipressin alone for the treatment of acute variceal hemorrhage in cirrhotic patients: a multicenter, double-blind study. Hepatology 1993;18:1102-7

[11] Giannini EG, Savarino V. Thrombocytopenia in liver disease. Current Opinion in Hematology 2008; 15:473-80.

[12] Tripodi A, Primignani M, Chantarangkul V, et al. Thrombin generation in patients with cirrhosis: the role of platelets. Hepatology 2006;44:440-5.

[13] Seeff LB, Everson GT, Morgan TR, et al. Complication rate of percutaneous liver biopsies among persons with advanced chronic liver disease in the HALT-C trial. Clinical Gastroenterology and Hepatology 2010;8:877-83.

[14] Tripodi A, Primignani M, Chantarangkul V, et al. Global hemostasis tests in patients with cirrhosis before and after prophylactic platelet transfusion. Liver International 2013:33:362-7.

[15] Ewe K. Bleeding after liver biopsy does not correlate with indices of peripheral coagulation. Digestive Diseases and Sciences 1981;26:388-93.

[16] McGill DB, Rakela J, Zinsmeister AR, et al. A 21-year experience with major hemorrhage after percutaneous liver biopsy. Gastroenterology 1990;99:1396-400.

[17] Diaz LK, Teruya J. Liver biopsy. New England Journal of Medicine 2001:344:2030

[18] Terjung B, Lemnitzer I, Dumoulin FL, et al. Bleeding complications after percutaneous liver biopsy: an analysis of risk factors. Digestion 2003;67:138-45

[19] Grabau CM, Crago SF, Hoff LK, et al. Performance standards for therapeutic abdominal paracentesis. Hepatology 2004;40:484-8.

[20] Segal JB, Dzik WH. Paucity of studies to support that abnormal coagulation test results predict bleeding in the setting of invasive procedures: an evidencebased review. Transfusion 2005;45:1413-25.

[21] Boks AL, Brommer EJ, Schalm SW, et al. Hemostasis and fibrinolysis in severe liver failure and their relation to hemorrhage. Hepatology 1986;6:79-86.

[22] Vieira da Rocha EC, D'Amico EA, Caldwell SH, et al. A prospective study of conventional and expanded coagulation indices in predicting ulcer bleeding after variceal band ligation. Clinical Gastroenterology and Hepatology 2009; 7:988-93

[23] Bosch J, Thabut D, Bendtsen F, et al. Recombinant factor VIIa for upper gastrointestinal bleeding in patients with cirrhosis: a randomized, double-blind trial. Gastroenterology 2004;127:1123-30.

[24] Bosch J, Thabut D, Albillos A, et al. Recombinant factor VIIa for variceal bleeding in patients with advanced cirrhosis: a randomized, controlled trial. Hepatology 2008;47:1604-14.

[25] Lodge JP, Jonas S, Jones RM, et al. Efficacy and safety of repeated perioperative doses of recombinant factor VIIa in liver transplantation. Liver Transplantation 2005;11:973-9.

[26] Planinsic RM, van der Meer J, Testa G, et al. Safety and efficacy of a single bolus administration of recombinant factor VIIa in liver transplantation due to chronic liver disease. Liver Transplantation 2005;11:895-900.

[27] Wang SC, Lin HT, Chang KY, et al. Use of higher thromboelastogram transfusion values is not associated with greater blood loss in liver transplant surgery. Liver Transplantation 2012;18:1254-8.

[28] Wang SC, Shieh JF, Chang KY, et al. Thromboelastography-guided transfusion decreases intraoperative blood transfusion during orthotopic liver transplantation: randomized clinical trial. Transplantation Proceedings 2010;42:2590-3

[29] Tripodi A, Primignani M, Chantarangkul V, et al. An imbalance of pro- vs anticoagulation factors in plasma from patients with cirrhosis. Gastroenterology 2009; 137:2105-11.

[30] Violi F, Ferro D, Basili S, et al. Hyperfibrinolysis increases the risk of gastrointestinal hemorrhage in patients with advanced cirrhosis. Hepatology 1992:15:672-6.

[31] Caldwell SH, Hoffman M, Lisman T, et al. Coagulation disorders and hemostasis in liver disease: pathophysiology and critical assessment of current management. Hepatology 2006;44:1039-46.

[32] Colucci M, Binetti BM, Branca MG, et al. Deficiency of thrombin activatable fibrinolysis inhibitor in cirrhosis is associated with increased plasma fibrinolysis. Hepatology 2003;38:230-7.

[33] Rijken DC, Kock EL, Guimarães AH, et al. Evidence for an enhanced fibrinolytic capacity in cirrhosis as measured with two different global fibrinolysis tests. Journal of Thrombosis and Haemostasis 2012;10:2116-22.

[34] Qi X, Chen H, Han G. Effect of antithrombin, protein C and protein S on portal vein thrombosis in liver cirrhosis: a meta-analysis. American Journal of the Medical Sciences 2013;346:38-44. 
[35] Amitrano L, Brancaccio V, Guardascione MA, et al. Inherited coagulation disorders in cirrhotic patients with portal vein thrombosis. Hepatology 2000;31:345-8.

[36] Martinelli I, Primignani M, Aghemo A, et al. High levels of factor VIII and risk of extra-hepatic portal vein obstruction. Journal of Hepatology 2009;50:916-22.

[37] Tripodi A, Primignani M, Lemma L, et al. Detection of the imbalance of pro- vs anti-coagulant factors in cirrhosis by a simple laboratory method. Hepatology 2010;52:249-55

[38] Trotter JF, Brimhall B, Arjal R. Specific laboratory methodologies achieve higher model for endstage liver disease (MELD) scores for patients listed for liver transplantation. Liver Transplantation 2004;10:995-1000.

[39] Tripodi A, Chantarangkul V, Mannucci PM. The international normalized ratio to prioritize patients for liver transplantation: problems and possible solutions. Journal of Thrombosis and Haemostasis 2008;6:243-8.

[40] Tripodi A, Chantarangkul V, Primignani M, et al. The international normalized ratio calibrated for cirrhosis (INRliver) normalizes prothrombin time results for model for end-stage liver disease calculation. Hepatology 2007;46:520-7.

[41] Bellest L, Eschwege V, Poupon R, et al. A modified international normalized ratio as an effective way of prothrombin time standardization in hepatology. Hepatology 2007;46:528-34.

[42] Northup PG, McMahon MM, Ruhl AP, et al. Coagulopathy does not fully protect hospitalized cirrhosis patients from peripheral venous thromboembolism. American Journal of Gastroenterology 2006;101:1524-8.

[43] Søgaard KK, Horváth-Puhó E, Grønbaek H, et al. Risk of venous thromboembolism in patients with liver disease: a nationwide population-based case-control study. American Journal of Gastroenterology 2009;104:96-101.

[44] Rodriguez-Castro KI, Simioni P, Burra P, et al. Anticoagulation for the treatment of thrombotic complications in patients with cirrhosis. Liver International 2012;32:1465-76.

[45] Bechmann LP, Wichert M, Kröger $K$, et al. Dosing and monitoring of low-molecular-weight heparin in cirrhotic patients. Liver International 2011;31:1064.

[46] Lisman T, Porte RJ. Towards a rational use of low-molecular-weight heparin in patients with cirrhosis. Liver International 2011;31:1063.

[47] Senzolo M, Rodriguez Kryssia I, Rossetto V, et al. Increased anticoagulant response to low molecular weight heparin in plasma from patients with advanced cirrhosis. Journal of Thrombosis and Haemostasis 2012;10:1823-9.

[48] Villa E, Cammà C, Marietta M, et al. Enoxaparin prevents portal vein thrombosis and liver decompensation in patients with advanced cirrhosis. Gastroenterology 2012;143:1253-60.

[49] Louie KS, Micallef JM, Pimenta JM, et al. Prevalence of thrombocytopenia among patients with chronic hepatitis C: a systematic review. Journal of Viral Hepatitis 2011;18:1-7.

[50] Weksler BB. The pathophysiology of thrombocytopenia in hepatitis C virus infection and chronic liver disease. Alimentary Pharmacology and Therapeutics 2007;26(Suppl 1):13-9.

[51] Latvala J, Parkkila S, Niemelä O. Excess alcohol consumption is common in patients with cytopenia: studies in blood and bone marrow cells. Alcoholism, Clinical and Experimental Research 2004;28:619-24.

[52] Torres Duarte AP, Dong QS, Young J, et al. Inhibition of platelet aggregation in whole blood by alcohol. Thrombosis Research 1995;78:107-15.

[53] Zhang QH, Das K, Siddiqui S, et al. Effects of acute, moderate ethanol consumption on human platelet aggregation in platelet-rich plasma and whole blood. Alcoholism, Clinical and Experimental Research 2000;24:528-34.

[54] Seth D, Hogg PJ, Gorrell MD, et al. Direct effects of alcohol on hepatic fibrinolytic balance: implications for alcoholic liver disease. Journal of Hepatology 2008;48:614-27.

[55] Pieters M, Vorster HH, Jerling JC, et al. The effect of ethanol and its metabolism on fibrinolysis. Thrombosis and Haemostasis 2010;104:724-33.

[56] Sengal H, Cottam S, Potter D, et al. Coagulation and fibrinolysis in primary biliary cirrhosis compared with other liver diseases and during orthotopic liver transplantation. Hepatology 1997;25:683-8.

[57] Pihusch R, Rank A, Gohring P, et al. Platelet function rather than plasmatic coagulation explains hypercoagulable state in cholestatic liver disease. Journal of Hepatology 2002;37:548-55.

[58] Biagini MR, Tozzi A, Marcucci R, et al. Hyperhomocysteinemia and hypercoagulability in primary biliary cirrhosis. World Journal of Gastroenterology 2006;12:1607-12.

[59] Tripodi A, Fracanzani AL, Primignani M, et al. Procoagulant imbalance in patients with non-alcoholic fatty liver disease. Journal of Hepatology 2014;61:148-54

[60] Sayed D, Amin NF, Galal GM. Monocyte-platelet aggregates and platelet micro-particles in patients with post-hepatitic liver cirrhosis. Thrombosis Research 2010;125:e228-33.

[61] Wiest R, Groszmann RJ. The paradox of nitric oxide in cirrhosis and portal hypertension: too much, not enough. Hepatology 2002;35:478-91.

[62] Annie-Jeyachristy S, Geetha A, Surendran R. Changes in the level of cytosolic calcium, nitric oxide and nitric oxide synthase activity during platelet aggregation: an in vitro study in platelets from normal subjects and those with cirrhosis. Journal of Biosciences 2008;33:45-53.

[63] Berzigotti A, Erice E, Gilabert R, et al. Cardiovascular risk factors and systemic endothelial function in patients with cirrhosis. American Journal of Gastroenterology 2013;108:75-82.

[64] Albornoz L, Alvarez D, Otaso JC, et al. Von Willebrand factor could be an index of endothelial dysfunction in patients with cirrhosis: relationship to degree of liver failure and nitric oxide levels. Journal of Hepatology 1999;30:451-5.
[65] Ferlitsch M, Reiberger T, Hoke M, et al. Von Willebrand factor as new noninvasive predictor of portal hypertension, decompensation and mortality in patients with liver cirrhosis. Hepatology 2012;56:1439-47.

[66] La Mura V, Reverter JC, Flores-Arroyo A, et al. Von Willebrand factor levels predict clinical outcome in patients with cirrhosis and portal hypertension. Gut 2011;60:1133-8.

[67] Wannhoff A, Müller OJ, Friedrich K, et al. Effects of increased von Willebrand factor levels on primary hemostasis in thrombocytopenic patients with liver cirrhosis. PLOS ONE 2014;9:e112583.

[68] Ferro D, Quintarelli C, Lattuada A, et al. High plasma levels of von Willebrand factor as a marker of endothelial perturbation in cirrhosis: relationship to endotoxemia. Hepatology 1996;23:1377-83.

[69] Borzio M, Salerno F, Piantoni L, et al. Bacterial infection in patients with advanced cirrhosis: a multicentre prospective study. Digestive and Liver Disease 2001;33:41-8.

[70] Moreau R, Jalan R, Gines P, et al. Acute-on-chronic liver failure is a distinct syndrome that develops in patients with acute decompensation of cirrhosis. Gastroenterology 2013;144:1426-37.

[71] Vincent JL, Yagushi A, Pradier O. Platelet function in sepsis. Critical Care Medicine 2002;30:S313-7.

[72] Ferro D, Basili S, Lattuada A, et al. Systemic clotting activation by lowgrade endotoxaemia in liver cirrhosis: a potential role for endothelial procoagulant activation. Italian Journal of Gastroenterology and Hepatology 1997;29:434-40.

[73] Grignani G, Maiolo A. Cytokines and hemostasis. Haematologica 2000;85:967-72

[74] Amitrano L, Guardascione MA, Brancaccio V, et al. Coagulation disorders in liver disease. Seminars in Liver Disease 2002;22:83-96.

[75] Montalto P, Vlachogiannakos J, Cox DJ, et al. Bacterial infection in cirrhosis impairs coagulation by a heparin effect: a prospective study. Journal of Hepatology 2002;37:463-70.

[76] Zambruni A, Thalheimer U, Leandro G, et al. Thromboelastography with citrated blood: comparability with native blood, stability of citrate storage and effect of repeated sampling. Blood Coagulation and Fibrinolysis 2004; $15: 103-7$

[77] Senzolo M, Riddell A, Tuddenham E, et al. Endogenous heparinoids contribute to coagulopathy in patients with liver disease. Journal of Hepatology 2008;48:371-2.

[78] Plessier A, Denninger MH, Consigny Y, et al. Coagulation disorders in patients with cirrhosis and severe sepsis. Liver International 2003;23:440-8.

[79] Reuken PA, Kussmann A, Kiehntopf M, et al. Imbalance of von Willebrand factor and its cleaving protease ADAMTS13 during systemic inflammation superimposed on advanced cirrhosis. Liver International 2015;35: 37-45.

[80] Violi F, Ferro D, Basili S, et al. Ongoing prothrombotic state in the portal circulation of cirrhotic patients. Thrombosis and Haemostasis 1997;77: 44-7.

[81] Soares-Weiser K, Brezis M, Tur-Kapsa R, et al. Antibiotic prophylaxis of bacterial infections in cirrhotic inpatients: a meta-analysis of randomized controlled trials. Scandinavian Journal of Gastroenterology 2003;38: $193-200$.

[82] Hou MC, Lin HC, Liu TT, et al. Antibiotic prophylaxis after endoscopic therapy prevents rebleeding in acute variceal hemorrhage: a randomized trial. Hepatology 2004;39:746-53.

[83] Piano S, Rosi S, Maresio G, et al. Evaluation of the Acute Kidney Injury Network criteria in hospitalized patients with cirrhosis and ascites. Journal of Hepatology 2013;59:482-9.

[84] Fagundes C, Barreto R, Guevara M, et al. A modified acute kidney injury classification for diagnosis and risk stratification of impairment of kidney function in cirrhosis. Journal of Hepatology 2013;59:474-81.

[85] Go AS, Chertow GM, Fan D, et al. Chronic kidney disease and the risks of death, cardiovascular events, and hospitalization. New England Journal of Medicine 2004;351:1296-305.

[86] Mahmoodi BK, Gansevoort RT, Næss IA, et al. Association of mild to moderate chronic kidney disease with venous thromboembolism: pooled analysis of five prospective general population cohorts. Circulation 2012;126 1964-71.

[87] Lutz J, Menke J, Sollinger D, et al. Haemostasis in chronic kidney disease. Nephrology, Dialysis, Transplantation 2014;29:29-40.

[88] De Gottardi A, Thévenot T, Spahr L, et al. Risk of complications after diagnostic paracentesis in cirrhotic patients: a prospective study. Clinical Gastroenterology and Hepatology 2009;7:906-9.

[89] Pache I, Bilodeau M. Severe haemorrhage following abdominal paracentesis for ascites in patients with liver disease. Alimentary Pharmacology and Therapeutics 2005;21:525-9.

[90] Lin CH, Shih FY, Ma MH, et al. Should bleeding tendency deter abdomina paracentesis. Digestive and Liver Disease 2005;37:946-51.

[91] Webster ST, Brown KL, Lucey MR, et al. Hemorrhagic complications of large volume abdominal paracentesis. American Journal of Gastroenterology 1996;91:366-8.

[92] Castellote J, Xiol X, Cortés-Beut R, et al. Complications of thoracentesis in cirrhotic patients with pleural effusion. Revista Espanola de Enfermedades Digestivas 2001;93:566-75.

[93] Xiol X, Castellote J, Cortes-Beut R, et al. Usefulness and complications of thoracentesis in cirrhotic patients. American Journal of Medicine 2001;111: 67-9. 
[94] Piccinino F, Sagnelli E, Pasquale G, et al. Complications following percutaneous liver biopsy. A multicentre retrospective study on 68,276 biopsies. Journal of Hepatology 1986;2:165-73.

[95] Actis GC, Olivero A, Lagget M, et al. The practice of percutaneous liver biopsy in a gastrohepatology day hospital: a retrospective study on 835 biopsies. Digestive Diseases and Sciences 2007;52:2576-9.

[96] Caturelli E, Giacobbe A, Facciorusso D, et al. Percutaneous biopsy in diffuse liver disease: increasing diagnostic yield and decreasing complication rate by routine ultrasound assessment of puncture site. American Journal of Gastroenterology 1996;91:1318-21.

[97] West J, Card TR. Reduced mortality rates following elective percutaneous liver biopsies. Gastroenterology 2010;139:1230-7.

[98] Kalambokis G, Manousou P, Vibhakorn S, et al. Transjugular liver biopsy-indications, adequacy, quality of specimens, and complications-a systematic review. Journal of Hepatology 2007;47:284-94.

[99] Bosch J, Abraldes JG, Berzigotti A, et al. The clinical use of HVPG measurements in chronic liver disease. Nature Reviews Gastroenterology \& Hepatology 2009;6:573-82

[100] Woolfson J, John P, Kamath B, et al. Measurement of hepatic venous pressure gradient is feasible and safe in children. Journal of Pediatric Gastroenterology and Nutrition 2013:57:634-7.

[101] Ward BB, Weideman EM. Long-term postoperative bleeding after dentoalveolar surgery in the pretransplant liver failure patient. Journal of Oral and Maxillofacial Surgery 2006;64:1469-74.

[102] Perdigão JP, de Almeida PC, Rocha TD, et al. Postoperative bleeding after denta extraction in liver pretransplant patients. Journal of Oral and Maxillofacial Surgery 2012;70:e177-84

[103] Vanbiervliet G, Giudicelli-Bornard S, Piche T, et al. Predictive factors of bleeding related to post-banding ulcer following endoscopic variceal ligation in cirrhotic patients: a case-control study. Alimentary Pharmacology and Therapeutics 2010;32:225-32.

[104] Lee S, Park SJ, Cheon JH, et al. Child-Pugh score is an independent risk factor fo immediate bleeding after colonoscopic polypectomy in liver cirrhosis. Yonse Medical Journal 2014;55:225-32

[105] Jeon JW, Shin HP, Lee JI, et al. The risk of postpolypectomy bleeding during colonoscopy in patients with early liver cirrhosis. Surgical Endoscopy 2012;11:3258-63.

[106] Livraghi T, Meloni F, Di Stasi M, et al. Sustained complete response and complications rates after radiofrequency ablation of very early hepatocellula carcinoma in cirrhosis: is resection still the treatment of choice? Hepatology 2008; $47: 82-9$

[107] Cammà C, Di Marco V, Orlando A, et al. Treatment of hepatocellular carcinom in compensated cirrhosis with radio-frequency thermal ablation (RFTA): a prospective study. Journal of Hepatology 2005;42:535-40.

[108] Shiina S, Teratani T, Obi S, et al. A randomized controlled trial of radiofrequency ablation with ethanol injection for small hepatocellular carcinoma. Gastroenterology 2005;129:122-30.

[109] Goto E, Tateishi R, Shiina S, et al. Hemorrhagic complications of percutaneous radiofrequency ablation for liver tumors. Journal of Clinical Gastroenterology 2010:44:374-80.

[110] McCluskey SA, Karkouti K, Wijeysundera DN, et al. Derivation of a risk index for the prediction of massive blood transfusion in liver transplantation. Liver Transplantation 2006;12:1584-93.

[111] Massicotte L, Beaulieu D, Thibeault L, et al. Coagulation defects do not predict blood product requirements during liver transplantation. Transplantation 2008;85:956-62.

[112] Massicotte L, Denault AY, Beaulieu D, et al. Transfusion rate for 500 consecutive liver transplantations: experience of one liver transplantation center Transplantation 2012;93:1276-81.

[113] Esmat Gamil M, Pirenne J, Van Malenstein $H$, et al. Risk factors for bleeding and clinical implications in patients undergoing liver transplantation. Transplantation Proceedings 2012;44:2857-60

[114] Kubo S, Takemura S, Yamamoto S, et al. Risk factors for massive blood los during liver resection for hepatocellular carcinoma in patients with cirrhosis. Hepato-Gastroenterology 2007;54:830-3.

[115] Delis S, Bakoyiannis A, Madariaga J, et al. Laparoscopic cholecystectomy in cirrhotic patients: the value of MELD score and Child-Pugh classification in predicting outcome. Surgical Endoscopy 2010;24:407-12.

[116] da Silveira EB. Outcome of cirrhotic patients undergoing cholecystectomy: applying Bayesian analysis in gastroenterology. Journal of Gastroenterology and Hepatology 2006;21:958-62.

[117] Ammar SA. Management of complicated umbilical hernias in cirrhotic patients using permanent mesh: randomized clinical trial. Hernia 2010;14:35-8

[118] Carbonell AM, Wolfe LG, De Maria EJ. Poor outcomes in cirrhosis-associated hernia repair: a nationwide cohort study of 32,033 patients. Hernia 2005;9:353-7

[119] Hedner U, Lee CA. First 20 years with recombinant FVIIa (NoveSeven) Haemophilia 2010;17:e172-82.

[120] Shao YF, Yang JM, Chau GY, et al. Safety and hemostatic effect of recombinant activated factor VII in cirrhotic patients undergoing partial hepatectomy: a multicenter, randomized, double-blind, placebo-controlled trial. American Journal of Surgery 2006;191:245-9.

[121] Bernstein DE, Jeffers L, Erhardtsen E, et al. Recombinant factor VIla corrects prothrombin time in cirrhotic patients: a preliminary study. Gastroenterology 1997;113:1930-7
[122] Chuansumrit A, Treepongkaruna S, Phuapradit P. Combined fresh frozen plasma with recombinant factor VIla in restoring hemostasis for invasive procedures in children with liver diseases. Thrombosis and Haemostasis 2001;85:748-9.

[123] Chuansumrit A, Chantarojanasiri T, Isarangkura $\mathrm{P}$, et al. Recombinant activated factor VII in children with acute bleeding resulting from liver failure and disseminated intravascular coagulation. Blood Coagulation and Fibrinolysis 2000;11(Suppl 1):s101-5.

[124] Jeffers L, Chalasani N, Balart L, et al. Safety and efficacy of recombinant Factor VIla in patients with liver disease undergoing laparoscopic liver biopsy. Gastroenterology 2002;123:118-26.

[125] Romero-Castro R, Jimenez-Saenz M, Pellicer-Bautista F, et al. Recombinantactivated factor VII as hemostatic therapy in eight cases of severe hemorrhage from esophageal varices. Clinical Gastroenterology and Hepatology 2004;2:78-84.

[126] Lodge JPA, Jonas S, Oussoultzoglou E, et al. Recombinant coagulation factor VIIa in major liver resection: a randomized, placebo-controlled, double-blind clinical trial. Anesthesiology 2005;102:269-75.

[127] Chavez-Tapia NC, Alfaro-Lara R, Tellez-Avila F, et al. Prophylactic activated recombinant factor VII in liver resection and liver transplantation: systematic review and meta-analysis. PLoS ONE 2011;6:e22581.

[128] Peck-Radosavljenic M. Thrombocytopenia in liver disease. Canadian Journa of Gastroenterology 2000;14(Suppl D):60D-6D.

[129] Poordad F. Thrombocytopenia in chronic liver disease. Alimentary Pharmacology and Therapeutics 2007;26(Suppl 1):5-11.

[130] Afdhal N, McHutchison J, Brown R, et al. Thrombocytopenia associated with chronic liver disease. Journal of Hepatology 2008;48:1000-7.

[131] Violi F, Pignatelli P. Eltrombopag before procedures in patients with cirrhosis and thrombocytopenia. New England Journal of Medicine 2012;367:2056.

[132] Luengo JI, Duffy KJ, Shaw AN, et al. Discovery of SB-497115, a small-molecule thrombopoietin (TPO) receptor agonist for the treatment of thrombocytopenia. Blood 2004;104:2910A

[133] Jenkins JM, Williams D, Deng Y, et al. Phase I clinical study of eltrombopag, an oral, nonpeptide thrombopoietin receptor agonist. Blood 2007;109:4739-41.

[134] Sellers T, Hart T, Semanik M, et al. Pharmacology and safety of SB-497115- GR an orally active small molecular weight TPO receptor agonist, in chimpanzees, rats and dogs. Blood 2004;104:2063A.

[135] Afdhal H, Dusheiko GM, Giannini EG, et al. Eltrombopag increases platelet numbers in thrombocytopenic patients with HCV infection and cirrhosis, allowing for effective antiviral therapy. Gastroenterology 2014;146:442-51.

[136] Afdhal NH, Giannini EG, Tayyab G, et al. Eltrombopag before procedures in patients with cirrhosis and thrombocytopenia. New England Journal of Medicine 2012;367:716-24.

[137] Martí-Carvajal AJ, Solà I. Vitamin K for upper gastrointestinal bleeding in patients with acute or chronic liver diseases. The Cochrane Database of Systematic Reviews 2012;9:CD004792.

[138] Pereira SP, Rowbotham D, Fitt D, et al. Pharmacokinetics and efficacy of oral versus intravenous mixed-micellar phylloquinone (vitamin K1) in severe acute liver disease. Journal of Hepatology 2005;42:365-70.

[139] Saja MF, Abdo A, Sanai FM, et al. The coagulopathy of liver disease: does vitamin K help? Blood Coagulation and Fibrinolysis 2013;24:10-7.

[140] Everson GT. A hepatologist's perspective on the management of coagulation disorders before liver transplantation. Liver Transplantation and Surgery 1997;3:646-52.

[141] Maltz GS, Siegel JE, Carson JL. Hematologic management of gastrointestina bleeding. Gastroenterology Clinics of North America 2000;29:169-87.

[142] Mueller MM, Bomke B, Seifried E. Fresh frozen plasma in patients with disseminated intravascular coagulation or in patients with liver diseases. Thrombosis Research 2002;107(Suppl 1):S9-17.

[143] Vlavianos P, Mac MP, Williamns R, et al. Splanchnic and systemic haemodynamic response to volume changes in patients with cirrhosis and portal hypertension. Clinical Science (London) 1999;96:475-81.

[144] Martin DJ, Lucas CE, Ledgerwood AM, et al. Fresh frozen plasma supplement to massive red blood cell transfusion. Annals of Surgery 1985;202:505-11.

[145] Gazzard BG, Henderson JM, Williams R. The use of fresh frozen plasma or a concentrate of factor IX as replacement therapy before liver biopsy. Gut 1975:16:621-5.

[146] Youssef WI, Salazar F, Dasarathy S, et al. Role of fresh frozen plasma infusion in correction of coagulopathy of chronic liver disease: a dual phase study. American Journal of Gastroenterology 2003;98:1391-4.

[147] Spector I, Corn M, Ticktin HE. Effect of plasma transfusions on the prothrombin time and clotting factors in liver disease. New England Journal of Medicine $1966 ; 275: 1032-7$.

[148] Tripodi A, Chantarangkul V Primignani M, et al. Thrombin generation in plasma from patients with cirrhosis supplemented with normal plasma: considerations on the efficacy of treatment with fresh-frozen plasma. Internal and Emergency Medicine 2012;7:139-44.

[149] Mannucci PM, Franchi F, Dioguardi N. Correction of abnormal coagulation in chronic liver disease by combined use of fresh-frozen plasma and prothrombin complex concentrates. Lancet 1976;2:542-5.

[150] Sorensen B, Spahn DR, Innerhofer P, et al. Clinical review: Prothrombin complex concentrates: evaluation of safety and thrombogenicity. Critical Care 2011;15:201

[151] Dentali F, Marchesi C, Pierfranceschi MG, et al. Safety of prothrombin complex concentrates for rapid anticoagulation reversal of vitamin $\mathrm{K}$ antagonists. A meta-analysis. Thrombosis and Haemostasis 2011;106:429-38. 
[152] Lorenz R, Kienast J, Otto U, et al. Efficacy and safety of a prothrombin complex concentrate with two virus-inactivation steps in patients with severe liver damage. European Journal of Gastroenterology and Hepatology 2003;15:15-20.

[153] Mannucci PM, Vicente V, Vianello L, et al. Controlled trial of desmopressin in liver cirrhosis and other conditions associated with a prolonged bleeding time. Blood 1986;67:1148-53.

[154] Burroughs AK, Matthews K, Qadiri M, et al. Desmopressin and bleeding time in patients with cirrhosis. British Medical Journal 1985;291:1377-81.

[155] Wong AY, Irwin MG, Hui TW, et al. Desmopressin does not decrease blood loss and transfusion requirements in patients undergoing hepatectomy. Canadian Journal of Anaesthesia 2003;50:14-20.

[156] Stanca CM, Montazem AH, Lawal A, et al. Intranasal desmopressin versus blood transfusion in cirrhotic patients with coagulopathy undergoing dental extraction: a randomized controlled trial. Journal of Oral and Maxillofacial Surgery 2010;68:138-43.

[157] Shore-Lesserson L. Point-of-care coagulation monitoring for cardiovascular patients: past and present. Journal of Cardiothoracic and Vascular Anesthesia 2002;16:99-106.

[158] Pereboom IT, de Boer MT, Porte RJ, et al. Aprotinin and nafamostat mesilate in liver surgery: effect on blood loss. Digestive Surgery 2007;24:282-7.

[159] Lentschener C, Benhamou D, Mercier FJ, et al. Aprotinin reduces blood loss in patients undergoing elective liver resection. Anesthesia and Analgesia 1997;84:875-81.

[160] Shimada M, Matsumata T, Shirabe K, et al. Effect of nafamostat mesilate on coagulation and fibrinolysis in hepatic resection. Journal of the American College of Surgeons 1994;178:498-502.

[161] Franchini M, Mannucci PM. Adjunct agents for bleeding. Current Opinion in Hematology 2014;21:503-8.

[162] Dalmau A, Sabate A, Acosta F, et al. Tranexamic acid reduces red cell transfusion better than epsilon-aminocaproic acid or placebo in liver transplantation. Anesthesia and Analgesia 2000;91:29-34.

[163] Wu CC, Ho WM, Cheng SB, et al. Perioperative parenteral tranexamic acid in liver tumor resection: a prospective randomized trial toward a blood transfusion-free hepatectomy. Annals of Surgery 2006;243:173-80.

[164] Molenaar IQ, Warnaar N, Groen H, et al. Efficacy and safety of antifibrinolytic drugs in liver transplantation: a systematic review and meta-analysis. American Journal of Transplantation 2007; 7:185-94.

[165] McCormick PA, Ooi H, Crosbie O. Tranexamic acid for severe bleeding gastric antral vascular ectasia in cirrhosis. Gut 1998;42:750-2.

[166] Garcia-Fuster MJ, Abdlla N, Fabia MJ, et al. Venous thromboembolism and liver cirrhosis. Revista Espanola de Enfermedades Digestivas 2008;100:259-62.

[167] Dabbagh O, Oza A, Prakash S, et al. Coagulopathy does not protect against venous thromboembolism in hospitalized patients with chronic liver disease. Chest 2010;137:1145-9.

[168] Huerta C, Johansson S, Wallander MA, et al. Risk factors and short-term mortality of venous thromboembolism diagnosed in the primary care setting in the United Kingdom. Archives of Internal Medicine 2007;167:935-43.

[169] Gulley D, Teal E, Suvannasankha A, et al. Deep vein thrombosis and pulmonary embolism in cirrhosis patients. Digestive Diseases and Sciences 2008;53:3012-7.

[170] Anthony Lizarraga W, Dalia S, Reinert SE, et al. Venous thrombosis in patients with chronic liver disease. Blood Coagulation and Fibrinolysis 2010;21:431-5.

[171] Aldawood A, Arabi Y, Aljumah A, et al. The incidence of venous thromboembolism and practice of deep venous thrombosis prophylaxis in hospitalized cirrhotic patients. Thrombosis Journal 2011;9:1-6.

[172] Lesmana CR, Inggriani S, Cahyadinata L, et al. Deep vein thrombosis in patients with advanced liver cirrhosis: a rare condition. Hepatology International 2010;4:433-8.

[173] Walsh KA, Lewis DA, Clifford TM, et al. Risk factors for venous thromboembolism in patients with chronic liver disease. Annals of Pharmacotherapy 2013;47:333-9.

[174] Wu H, Nguyen GC. Liver cirrhosis is associated with venous thromboembolism among hospitalized patients in a nationwide US study. Clinical Gastroenterology and Hepatology 2010;8:800-5.

[175] Saleh T, Matta F, Alali F, et al. Venous thromboembolism with chronic liver disease. American Journal of Medicine 2011:124:64-8.

[176] Ali M, Ananthakrishnan AN, McGinley EL, et al. Deep vein thrombosis and pulmonary embolism in hospitalized patients with cirrhosis: a nationwide analysis. Digestive Diseases and Sciences 2011;56:2152-9.

[177] Barclay SM, Jeffres MN, Nguyen K, et al. Evaluation of pharmacologic prophylaxis for venous thromboembolism in patients with chronic liver disease. Pharmacotherapy 2013;33:375-82.

[178] Intagliata NM, Henry ZH, Shah N, et al. Prophylactic anticoagulation for deep venous thrombosis in hospitalized cirrhosis patients is safe and does not lead to increased bleeding events. Hepatology 2011;54:1253A.

[179] Zocco MA, Stasio ED, Cristofaro RD, et al. Thrombotic risk factors in patients with liver cirrhosis: correlation with MELD scoring system and portal vein thrombosis development. Journal of Hepatology 2009;51:682-9.

[180] Maruyama H, Okugawa H, Takahashi M, et al. De novo portal vein thrombosis in virus-related cirrhosis: predictive factors and long-term outcomes. American Journal of Gastroenterology 2013;108:568-74.

[181] John BV, Konjeti R, Aggarwal A, et al. Impact of untreated portal vein thrombosis on pre and post liver transplant outcomes in cirrhosis. Annals of Hepatology 2013;12:952-8.
[182] Nery F, Chevret S, Condat B, et al. Causes and consequences of portal vein thrombosis in 1,243 patients with cirrhosis: results of a longitudinal study. Hepatology 2015;61:660-7.

[183] Violi F, Ferro D, Basili S, et al. Relation between lupus anticoagulant and splanchnic venous thrombosis in cirrhosis of the liver. British Medical Journal 1994;309:239-40.

[184] Amitrano L, Guardascione MA, Brancaccio V, et al. Risk factors and clinical presentation of portal vein thrombosis in patients with liver cirrhosis. Journal of Hepatology 2004;40:736-41.

[185] Robles R, Fernandez JA, Hernández Q et al. Eversion thromboendovenectomy in organized portal vein thrombosis during liver transplantation. Clinical Transplantation 2004; 18:79-84.

[186] Fimognari FL, De Santis A, Piccheri C, et al. Evaluation of D-dimer and factor VIII in cirrhotic patients with asymptomatic portal venous thrombosis. Journal of Laboratory and Clinical Medicine 2005;146:238-43.

[187] Lendoire J, Raffin G, Cejas N, et al. Liver transplantation in adult patients with portal vein thrombosis: risk factors, management and outcome. HPB (Oxford) 2007;9:352-6.

[188] Weber A, Krebs S, Lenhardt C, et al. Correlation of routinely used coagulation parameters and presence of portal vein thrombosis in patients with liver cirrhosis. Hepatology Research 2009;39:882-7.

[189] Girleanu I, Stanciu C, Cojocariu C, et al. Natural course of nonmalignant partial portal vein thrombosis in cirrhotic patients. Saudi Journal of Gastroenterology 2014;20:288-92

[190] Berry K, Taylor J, Liou IW, et al. Portal vein thrombosis is not associated with increased mortality among patients with cirrhosis. Clinical Gastroenterology and Hepatology 2015;13:585-93.

[191] Tsochatzis EA, Senzolo M, Germani G, et al. Systematic review: portal vein thrombosis in cirrhosis. Alimentary Pharmacology and Therapeutics 2010;31:366-74

[192] Primignani M. Portal vein thrombosis, revisited. Digestive and Liver Disease 2009:42:163-70.

[193] Garcia-Pagan JC, Valla DC. Portal vein thrombosis: a predictable milestone in cirrhosis? Journal of Hepatology 2009;51:632-4.

[194] Politoske D, Ralls P, Korula J. Portal vein thrombosis following endoscopic variceal sclerotherapy. Prospective controlled comparison in patients with cirrhosis. Digestive Diseases and Sciences 1996;41:185-90.

[195] Kawasaki S, Henderson JM, Riepe SP, et al. Endoscopic variceal sclerosis does not increase the risk of portal venous thrombosis. Gastroenterology 1992;102:206-15

[196] Mangia A, Margaglione M, Cascavilla I, et al. Anticardiolipin antibodies in patients with liver disease. American Journal of Gastroenterology 1999;94:2983-7.

[197] Romero Gomez M, Suarez Garcia E, Lopez Lacomba D, et al. Antiphospholipid antibodies are related to portal vein thrombosis in patients with liver cirrhosis. Journal of Clinical Gastroenterology 2000;31:237-40.

[198] Amitrano L, Guardascione MA, Ames PR, et al. Increased plasma prothrombin concentration in cirrhotic patients with portal vein thrombosis and prothrombin G20210A mutation. Thrombosis and Haemostasis 2006;95: 221-3.

[199] Piscaglia F, Gianstefani A, Ravaioli M, et al. Criteria for diagnosing benign portal vein thrombosis in the assessment of patients with cirrhosis and hepatocellular carcinoma for liver transplantation. Liver Transplantation 2010;16:658-67.

[200] Rossi S, Rosa L, Ravetta V, et al. Contrast-enhanced versus conventional and color Doppler sonography for the detection of thrombosis of the portal and hepatic venous systems. American Journal of Roentgenology 2006;186:1-11.

[201] Tarantino L, Francica G, Sordelli I, et al. Diagnosis of benign and malignant portal vein thrombosis in cirrhotic patients with hepatocellular carcinoma: color Doppler US, contrast-enhanced US, and fine needle biopsy. Abdominal Imaging 2006;31:537-44.

[202] Yerdel MA, Gunson B, Mirza D, et al. Portal vein thrombosis in adults undergoing liver transplantation: risk factors, screening, management, and outcome. Transplantation 2000;69:1873-81.

[203] Luca A, Caruso S, Milazzo M. Natural course of extrahepatic nonmalignant partial portal vein thrombosis in patients with cirrhosis. Radiology 2012:265:124-32.

[204] Senzolo M, Sartori T, Rossetto V, et al. Prospective evaluation of anticoagulation and transjugular intrahepatic portosystemic shunt for the management of portal vein thrombosis in cirrhosis. Liver International 2012;32:919-27.

[205] Englesbe MJ, Kubus J, Muhammad W, et al. Portal vein thrombosis and survival in patients with cirrhosis. Liver Transplantation 2010;16:83-90.

[206] Rodríguez-Castro KI, Porte RJ, Nadal E, et al. Management of nonneoplastic portal vein thrombosis in the setting of liver transplantation: a systematic review. Transplantation 2012;94:1145-53.

[207] Delgado MG, Seijo S, Yepes I, et al. Efficacy and safety of anticoagulation on patients with cirrhosis and portal vein thrombosis. Clinical Gastroenterology and Hepatology 2012;10:776-83.

[208] Amitrano L, Guardascione MA, Menchise A, et al. Safety and efficacy of anticoagulation therapy with low molecular weight heparin for portal vein thrombosis in patients with liver cirrhosis. Journal of Clinical Gastroenterology 2010;44:448-51.

[209] Francoz C, Belghiti J, Vilgrain V, et al. Splanchnic vein thrombosis in candidates for liver transplantation: usefulness of screening and anticoagulation. Gut 2005;54:691-7. 
[210] Werner KT, Sando S, Carey EJ, et al. Portal vein thrombosis in patients with end stage liver disease awaiting liver transplantation: outcome of anticoagulation. Digestive Diseases and Sciences 2013;58:1776-80.

[211] Francoz C, Valla D, Durand F. Portal vein thrombosis, cirrhosis, and liver transplantation. Journal of Hepatology 2012;57:203-12.
[212] Congly SE, Lee SS. Portal vein thrombosis: should anticoagulation be used? Current Gastroenterology Reports 2013;15:306.

[213] Kinjo N, Kawanaka H, Akahoshi T, et al. Portal Vein thrombosis in liver cirrhosis. World Journal of Hepatology 2014;6:64-71. 